\title{
SUBORDINATION AND SUPERORDINATION-PRESERVING PROPERTIES OF CERTAIN INTEGRAL OPERATOR
}

\author{
T. N. SHANMUGAM AND M. P. JEYARAMAN
}

Abstract. In the present investigation, we obtain subordination and superordination - preserving properties of certain integral operator with the sandwich type theorem.

Mathematics subject classification (2000): 30C45.

Key words and phrases: Subordination, superordination, best dominant and best subordinant.

\section{REFERENCES}

[1] T. BulboaCA, A class of superordination - preserving integral opertor, Indag. Math. 13(3), (2002) 301-311.

[2] N. E. CHO AND S. OwA, Double subordination - preserving properties for certain integral operators, J. Inequal. and Appl. Art 83073, Vol. 2007, (2007) pp. 1-10.

[3] S. S. Miller and P. T. Mocanu, Differential subordination and univalent functions, Michig. Math. J. 28 (1981), 157-171.

[4] S. S. Miller And P. T. Mocanu, Differential subordinations, Theory and Applications, Monographs and Textbooks in Pure and Applied Mathematics, Marcel Dekker, New York, USA, (2000).

[5] S. S. Miller AND P. T. Mocanu, Subordinants of differential superordinations, Complex variables, 48(10) (2003), 815-826.

[6] S. S. Miller, P. T. MocANU AND O. READE, Subordination - preserving integral operators, Transaction of the American Mathematical Society, 283(2), (1984), 605-615.

[7] P. T. Mocanu, Convexity and close to convexity preserving integral operators, Mathematica (cluj), 25 (1983), 177-182.

[8] CH. Pommerenke, Univalent Function, Vanderhoeck and Ruprecht, Gotlingen, 1975.

[9] RusCHEWEYH, Eine Invarianzeigenschaft der Bazilevic Functionen, Math. z., (134) (1973), 215-219.

[10] T. N. Shanmugam, Studies on analytic functions with special reference to integral opertors, Ph. D., Thesis, Anna University, Chennai, 1987. 